\title{
LA DIALÉCTICA MARXISTA Y EL HUMANISMO DE LA PRAXIS ${ }^{1}$
}

\author{
THE MARXIST DIALECTIC AND THE HUMANISM OF PRAXIS
}

A DIALÉTICA MARXISTA E O HUMANISMO DA PRÁXIS

\section{Franz J. Hinkelammert ${ }^{2}$}

\begin{abstract}
Resumen
En este artículo intento hacer ver una dialéctica de Marx que no consiste simplemente en "poner a Hegel de pie", sino que es, incluso, radicalmente distinta de la dialéctica hegeliana. Partiendo del "imperativo categórico" formulado por Marx en 1844, se concluye que este se encuentra también en El capital, y precisamente, en una parte decisiva de esta obra. Se trata de un humanismo de la praxis que es posible recuperar y seguir desarrollando para enfrentar las grandes amenazas de nuestro tiempo.

Palabras clave: dialéctica de Marx; dialéctica de Hegel; humanismo de la praxis; emancipación humana

\section{Summary}

In this article I try to see a "dialectic of Marx" that does not simply consist of "putting Hegel on his feet", but is even radically different from the Hegelian dialectic. Starting from the "categorical imperative" formulated by Marx in 1844, it is concluded that it is also found in Capital, and precisely in a decisive part of this work. It is a humanism of praxis that can be recovered and further developed to face the great threats of our time.
\end{abstract}

Doi: https://doi.org/10.15359/eys.24-55.6

Fecha de recepción: 13-03-2019. Fechas de reenvíos: 04-04-2019, 12-03-2019. Aceptado el 07-05-2019. Publicado el 10-05-2019.

${ }^{1}$ Una versión previa de este artículo fue publicada en el sitio en internet llamado Pensamiento Crítico, el cual es administrado por Franz Hinkelammert. http://pensamientocritico.info/

${ }^{2}$ Economista y teólogo alemán, exponente de la teología de la liberación y de la crítica teológica al capitalismo. Cofundador del Departamento Ecuménico de Investigaciones, en San José, Costa Rica. Doctor en Economía por la Universidad Libre de Berlín. Consultor independiente, Costa Rica.

134

Franz J. Hinkelammert

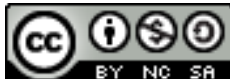

Revista Economía y Sociedad by Universidad Nacional is licensed under a CreativeCommons Reconocimiento-NoComercial- 
Keywords: Dialectics of Marx; dialectics of Hegel; humanism of praxis; human emancipation

\section{Resumo}

Neste artigo, tento mostrar uma dialética de Marx que não consiste simplesmente em "colocar Hegel em pé", mas que é, inclusive, radicalmente diferente da dialética hegeliana. Partindo do "imperativo categórico" formulado por Marx em 1844, conclui-se que isso também se encontra em $\mathrm{O}$ capital e, precisamente, em uma parte decisiva desta obra. Trata-se de um humanismo da práxis que pode ser recuperado e seguir sendo desenvolvido para enfrentar as grandes ameaças do nosso tempo.

Palavras-chaves: dialética de Marx; dialética de Hegel; humanismo da práxis; emancipação humana

Hoy es necesario hacernos de nuevo la siguiente pregunta: ¿cuál es el punto de partida del pensamiento de Marx? Pero no se trata de contestar esta pregunta la por nosotros mismos, sino de averiguar cómo Marx en su tiempo la respondió efectivamente. Por eso, quiero partir de un punto de vista que el mismo Marx expresa y del cual no se puede decir que se trate de un Marx "premarxista", o quien se pronuncia sobre esta cuestión no es todavía el pretendido "Marx maduro", como muchas veces fue argumentado por Louis Althusser.

\section{¿Cómo el Marx de 1859 ve al Marx del año 1844 y su “Crítica de la filosofía del derecho de Hegel - Introducción"?}

En el prólogo de su libro Contribución a la crítica de la economía política del año 1859, Marx reflexiona sobre sus estudios precedentes. Dice entonces:

Mis estudios profesionales eran los de Jurisprudencia, de la que, sin embargo, sólo me preocupé como disciplina secundaria, al lado de la filosofía y de la historia. En 1842 - 1843, siendo redactor de la Rheinische Zeitung, me vi por vez primera en el trance difícil de tener que opinar acerca de los llamados intereses materiales. Los debates de la Dieta renana sobre la tala furtiva y la parcelación de la propiedad del suelo, la polémica oficial mantenida entre el señor Von Schaper, a la sazón gobernador de la provincia renana, y la Rheinische Zeitung, sobre la situación de los campesinos del Mosela, fue lo que me movió a ocuparme por vez primera de cuestiones económicas. Por otra parte, en aquellos tiempos en que el buen deseo de "marchar a la vanguardia" superaba con mucho el conocimiento de la materia, la Rheinische Zeitung dejaba traslucir un eco del socialismo y del comunismo francés, 
teñido de un tenue matiz filosófico. Yo me declaré en contra de aquellas chapucerías, pero confesando al mismo tiempo francamente, en una controversia con la Allgemeine Augsburger Zeitung, que mis estudios hasta entonces no me permitían aventurar ningún juicio acerca del contenido propiamente dicho de las tendencias francesas. (Marx, 1976a, pp. 10-11).

Después afirma Marx, que a partir de ese momento hubo de retirarse "de la escena pública a mi cuarto de estudio." Y añade: "Mi primer trabajo, emprendido para resolver las dudas que me asaltaban, fue una revisión crítica de la filosofía hegeliana del derecho, trabajo cuya introducción vio la luz en los Deutsch-Französische Jahrbücher, publicados en París en 1844". (Marx, 1976a, p. 11).

En esta crítica de Hegel (1844), Marx sostiene un quiebre con respecto a su pensamiento anterior, al que Marx precisamente (auto)critica con este artículo de 1844 y que en su prólogo de 1859 considera como el paso básico para todo su pensamiento posterior.

Por eso, tenemos que hacernos la pregunta, al poner la atención en este artículo de 1844, a ¿a cuál Marx se refiere Marx en 1859? No tengo ninguna duda de que se trata del siguiente resultado de su análisis de 1844: "La crítica de la religión desemboca en la doctrina de que el ser humano es el ser supremo para el ser humano y, por consiguiente, en el imperativo categórico de echar por tierra todas las relaciones en que el ser humano sea un ser humillado, sojuzgado, abandonado y despreciable". (Marx, citado en Fromm, 1964, p. 230).

Que el ser humano sea el ser supremo para el ser humano, significa, que el ser humano mismo es "el criterio" de la crítica. Y este criterio Marx lo llama, su imperativo categórico. De eso obtiene como consecuencia, que hay que "echar por tierra todas las relaciones en que el ser humano sea un ser humillado, sojuzgado, abandonado y despreciable", tal como aparece en la cita previa.

Se trata de un criterio de la acción. Marx no describe aquí sentimientos encontrados, sino una racionalidad de la acción económica y política, que es contraria a la racionalidad del mercado. Se trata para Marx de lo humano del ser humano. De manera que, para Marx la meta es transformar la humanidad del ser humano en el criterio central para el propio ser humano. Entonces, el imperativo categórico describe el camino necesario, mientras que la meta del camino es el ser humano como el ser supremo para el ser humano y, por tanto, la "emancipación humana'.

Se podría ahora añadir que en las teorías de la economía política burguesa analizadas por Marx, no es el ser humano el ser supremo para el ser humano, sino el mercado (y el dinero y el capital). La cuestión para Marx es la siguiente: ¿qué hacer para que el ser humano sea reconocido y tratado como el ser supremo para el ser humano? A este problema se dedicará por entero el resto de su vida.

136

Franz J. Hinkelammert

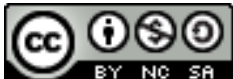

Revista Economía y Sociedad by Universidad Nacional is licensed under a CreativeCommons Reconocimiento-NoComercialCompartirlgual 4.0 Internacional License.

Creado a partir de la obra en http://www.revistas.una.ac.cr/index.php/economia 
Marx mismo muestra cuál es el centro de este artículo de 1844 (en el resumen), y escribe al final: "Resumamos el resultado. La única emancipación práctica posible de Alemania es la emancipación desde el punto de vista de la teoría, que declara que el ser humano es el ser supremo para el ser humano". (Marx, $\underline{1844}$, p. 8). ${ }^{3}$

Aquí contesta a posiciones francesas. La revolución francesa declaró la diosa razón como ser supremo para el ser humano. Marx, sin embargo, establece en contrario: el propio ser humano es el ser supremo para el ser humano. Sobre eso habla Marx en el prólogo de 1859 de su libro ya mencionado Contribución a la crítica de la economía política e indica los pasos que siguieron al artículo de 1844:

Mis investigaciones desembocaban en el resultado que sigue:

Tanto las relaciones jurídicas como las formas de Estado no pueden comprenderse por sí mismas ni por la llamada evolución general del espíritu humano, sino que radican, por el contrario, en las condiciones materiales de vida cuyo conjunto resume Hegel, siguiendo el precedente de los ingleses y franceses del siglo XVIII, bajo el nombre de "sociedad civil", y que la anatomía de la sociedad civil hay que buscarla en la economía política. (Marx, 1976a, pp.11-12).

Es decisiva la constatación de parte de Marx, de que la "anatomía de la sociedad civil hay que buscarla en la economía política".

Según Marx, la tesis de su artículo de 1844 de que el "ser humano es el ser supremo para el ser humano" le llevó al reconocimiento de que la "anatomía de la sociedad civil hay que buscarla en la economía política" [las condiciones materiales de vida], porque esta da los criterios concretos de juicio.

Ambas tesis se implican mutuamente. Como el ser humano es el ser supremo para el ser humano, la anatomía de la sociedad civil hay que buscarla en la economía política.

Posteriormente, Marx cambia la formulación de aquello que él destaca como el centro de su pensamiento, sin cambiar este mismo centro. En el Manifiesto del Partido Comunista habla de una futura asociación de hombres libres, en la cual "el libre desarrollo de cada uno es la condición para el libre desarrollo de todos".

Pero eso, no cambia el contenido central de la tesis. Decir que "el libre desarrollo de cada uno es la condición para el libre desarrollo de todos" es lo mismo que decir que "el ser humano es el ser

${ }^{3}$ He corregido en la traducción "esencia suprema" por "ser supremo". 
supremo para el ser humano". Por eso, en ambos casos está implicado que "la anatomía de la sociedad civil hay que buscarla en la economía política". Marx solamente cambió la formulación para evitar ciertos malentendidos.

\section{El humanismo de la praxis}

De esta manera, se ve que, para Marx, el artículo de 1844 es el fundamento a partir del cual tienen que ser entendidos todos sus estudios y teorías posteriores. Marx , y lo afirma 15 años después de su publicación, al haber escrito ya los Grundrisse (Elementos fundamentales para la crítica de la economía política 1857-1858) y el libro Contribución a la crítica de la economía política de 1859, en cuyo prólogo explica la importancia fundamental del artículo de 1844. Si uno quiere hablar en términos de Althusser, lo que Marx precisamente ha desarrollado en su artículo de 1844 es, según el propio Marx, su quiebre epistemológico, que sin embargo Althusser no menciona y que posiblemente, ni siquiera lo ha notado. Althusser habla de un quiebre epistemológico en Marx, que pretendidamente ocurre tiempo después y que lleva a Althusser a declarar artículos como el mencionado de 1844, como premarxistas o no-marxistas. De esta manera, Althusser declara un pensamiento central de Marx como "no-marxista", a pesar de que el mismo Marx en su prólogo sobre la crítica de la economía política del año 1859, lo presenta como el punto partida de todas sus teorías posteriores.

Según Marx, precisamente este artículo de 1844 es el "quiebre epistemológico" que le hacía falta hasta ese momento. Althusser tendría que haber discutido precisamente eso, porque Marx de todas maneras tiene que decidir si este artículo, de 1844 realmente es "marxista" o no (si se quiere usar esta polémica expresión althusseriana, "marxista" o "no-marxista", referiéndose al propio Marx).

Marx llamaba al día en que llegara el resultado de este pensamiento nuevo, el día de la resurrección de Alemania, que sería anunciado por el canto del gallo francés. Lo dice en la última frase del artículo de 1844: "Cuando todas las condiciones internas se realicen, el día de la resurrección alemana será anunciado por el canto resonante del gallo francés." (Marx, $\underline{1844}$, p. 9).

Lo que en realidad es importante de resaltar, es el hecho de que en 1859 Marx vuelve a revivir sus pensamientos fundamentales del año 1844 y sostiene esta su posición hasta el final de su vida, aunque cambia frecuentemente el tono de su lenguaje. Lo que Marx dice es que lo desarrollado en este artículo del año 1844 es el pensamiento fundamental de todo lo que va a ser desplegado y especificado en su pensamiento posterior. De todas maneras, podemos comprobar que Marx nunca presenta posiciones que no sean compatibles con lo que dice en este artículo del año 1844. Lo que sigue diciendo, también en el año 1859, es que el centro de su pensamiento era 
y es, que "el ser humano es el ser supremo para el ser humano", lo que llama en 1844 su "imperativo categórico".

Se trata precisamente de palabras de Marx que desde hace mucho tiempo apenas si se escuchan, pero que hoy pueden volver a tener preeminencia, después de que el neoliberalismo ha implantado una forma tan extrema de interpretación del capitalismo, como en la historia anterior no se había dado nunca. Se trata de la extrema abolición de lo humano, como lo expresa la señora Merkel en Alemania, cuando dice: "la democracia tiene que ser conforme al mercado". En forma absoluta se dice de hecho: el ser humano no es el ser supremo para el ser humano, sino el ser supremo para el ser humano es el mercado.

En la situación histórica de hoy se puede entender entonces, que la formulación por Marx de su pensamiento sobre la sociedad moderna se nos hace de nuevo consciente: el ser humano es el ser supremo para el ser humano. Se trata del ser humano, no del mercado, pero tampoco del dinero o del capital. Se trata de este ser humano como ser supremo para el ser humano, que en Marx desemboca en su humanismo de la praxis y que solamente acepta al ser humano como ser supremo para el ser humano en el grado en el cual desemboca en este humanismo de la praxis.

\section{Sobre algunas tesis de Althusser}

En relación con el tema que nos ocupa, Althusser afirma exactamente lo contrario de lo expresado por Marx. De hecho, lo dicho por Marx en el año 1859, suena como si Marx, antes de escribirlo, hubiera ya leído a Althusser, .... para contestarle. Podemos suponer que Marx en su prólogo de 1859 ya sospecha la posibilidad de que se pueda intentar hacer desaparecer lo que había sostenido en 1844, es decir, que el ser humano es el ser supremo para el ser humano. Según Engels, Marx ha dicho posteriormente en términos irónicos: "Todo lo que yo sé, es que yo no soy marxista." Posiblemente, quiere responder a esta posible tergiversación, ya en su prólogo de 1859.

Althusser hace presente la opinión contraria mencionada, que sin embargo hoy es compartida por muchos. Por esta razón, quisiera analizar algunas tesis de Althusser que pueden indicar las posiciones que él asume y a las cuales quiero contestar. Para la crítica de estas tesis utilizo una selección que hizo Marta Harnecker. Ella conoce muy bien el pensamiento de Althusser, mismo que ella difunde en América Latina, después de sus estudios en París, justamente en su libro: Los conceptos elementales del materialismo histórico (Harnecker, 1969). Ella, ha promovido mucho el conocimiento sobre Althusser en América Latina, cuyas posiciones no solamente difundía, sino que también las asumía personalmente. 


\section{Marx y Feuerbach}

Marta Harnecker dice sobre la relación entre Marx y Feuerbach, según la veía Althusser:

Marx en un momento asumió la problemática feuerbachiana. Una lectura crítica cuidadosa de Marx, como la que hizo Althusser al editar la traducción francesa de Feuerbach, demuestra que muchos de los párrafos que los marxistas humanistas citaban como propios de Marx, no eran sino copia de párrafos textuales de Feuerbach que Marx escribía para su uso personal ... El pensamiento original de Marx sólo surge en un momento de su desarrollo intelectual, cuando rompe con las problemáticas hegeliana y feuerbachiana con las que se había identificado previamente y en las cuales están inmersas sus obras de juventud..." Porque según Althusser: "Una nueva problemática significa siempre nuevos conceptos, en el caso de Marx: modo de producción, fuerzas productivas, relaciones de producción, plusvalía, etcétera." (Harnecker, 2016, p. 7) .

Desgraciadamente, Marta Harnecker no da ejemplos correspondientes para esta afirmación. Por eso, yo mismo voy a presentar un ejemplo, que a mi entender demuestra, que esa afirmación es equivocada. Primero quiero partir del análisis de un texto de Feuerbach y presento un ejemplo en el cual Feuerbach usa determinados conceptos, que posteriormente, también Marx usa. Se trata del siguiente texto: "Si la esencia del ser humano es la esencia suprema del ser humano, entonces prácticamente la suprema y primera ley tiene que ser el amor del ser humano hacia el ser humano." (Feuerbach, 1956, p. 508, traducción propia).

En seguida llama la atención la similitud de esta cita de Feuerbach con la cita de Marx, que ya he presentado antes, y que también habla del ser supremo para el ser humano. Para hacer más fácil la comparación, voy a repetir la correspondiente cita de Marx:

La crítica de la religión desemboca en la doctrina de que el ser humano es el ser supremo para el ser humano y, por consiguiente, en el imperativo categórico de echar por tierra todas las relaciones en que el ser humano sea un ser humillado, sojuzgado, abandonado y despreciable. (Marx citado en Fromm, 1964, p. 230).

Ambas citas consisten en una sola frase, que tiene dos partes. La primera parte habla del ser humano como ser supremo para el ser humano. Prácticamente, esta primera parte aparece igual en ambas citas; pero la manera de expresarse en el caso de Marx es más directa.

Sin embargo, la segunda parte en las dos citas es sumamente diferente. Feuerbach dice que la consecuencia de la primera parte es que la primera ley que sigue sea "el amor del ser humano 140

Franz J. Hinkelammert

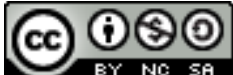

Revista Economía y Sociedad by Universidad Nacional is licensed under a CreativeCommons Reconocimiento-NoComercial- 
hacia el ser humano". Marx comparte eso sin problemas, pero, sin embargo, sostiene que la consecuencia es el imperativo categórico de "echar por tierra todas las relaciones en que el ser humano sea un ser humillado, sojuzgado, abandonado y despreciable". Esta concreción va obviamente, mucho más allá de lo que Feuerbach expresa.

Marx habla de una praxis de la acción, de un cambio de la propia relación con el mundo. En cambio, Feuerbach se dirige al mundo de los sentimientos, sin ninguna concretización de ninguna acción. El mundo de Feuerbach es un mundo como aquel de Schiller con su himno a la alegría y la novena sinfonía de Beethoven. Se trata de un mundo bello y armonioso, que solo muy indirectamente puede unirse con el mundo de la praxis. De por sí, no expresa ninguna praxis. Se trata de la imagen de un mundo bello. Marx en cambio dice con mucha claridad que quiere ir más allá de eso hacia un mundo más humano. Por eso, define una praxis. En su tesis XI sobre Feuerbach del año 1845 lo dice muy directamente: "Los filósofos no han hecho más que interpretar de diversos modos el mundo, pero de lo que se trata es de transformarlo." (Marx, $\underline{1976 b}$, p. 10).

Eso es un humanismo de la praxis, que Feuerbach no comparte y que para Marx significa un punto de partida, que él se propone desarrollar y que nunca va a abandonar.

\section{Marx y Hegel}

Un prejuicio como el que se presenta constantemente frente a Feuerbach, aparece igualmente, frente al pretendido ( $y$ de hecho muchas veces solo aparente), hegelianismo de Marx. Quisiera hacer también, sobre esto un breve comentario. Empiezo de nuevo con una reseña correspondiente de Marta Harnecker. Ella dice sobre una conversación que como estudiante tuvo con Althusser:

Él... me recomendó leer directamente a Marx empezando por El Capital, y no por sus páginas iniciales sino partiendo por el capítulo de la plusvalía, ya que en los primeros capítulos Marx había coqueteado — según él- con la dialéctica hegeliana. (Harnecker, 2016, p. 2 ).

Creo necesario discutir dónde realmente arranca la dialéctica de Marx y cómo se corresponde o no con la dialéctica de Hegel. Muy temprano Marx ya había dicho que Hegel estaba puesto de cabeza y que era necesario ponerlo sobre sus pies.

En lo siguiente quiero presentar algunas citas de Marx, por medio de las cuales se puede mostrar, lo que en realidad es del núcleo de la dialéctica de Marx: 
Las relaciones sociales que se establecen entre sus trabajos privados aparecen como lo que son: es decir, no como relaciones directamente sociales de las personas en sus trabajos, sino como relaciones materiales [sachliche! e.d. con carácter de cosas] entre personas y relaciones sociales entre cosas. (Marx, 1966, p. 38).

Según eso, a los propietarios de las mercancías sus relaciones entre ellos se les aparecen como relaciones materiales (sachliche! e.d. con carácter de cosas) entre personas y relaciones sociales entre cosas. Parece ser eso. Pero de hecho se trata de una manera determinada de ver la realidad social ("desde arriba"). Es la manera del observador, quien la mira y que considera que lo que él ve de esta manera es lo que es.

Según Marx, resulta una diferente manera de ver estas relaciones mercantiles ("desde abajo"), que surge cuando uno toma en cuenta no solamente su papel de observador, sino en cuanto que persona viva (sujeto viviente), que precisamente vive en el interior de estas relaciones mercantiles. Esta persona puede ahora vivir lo que las relaciones mercantiles no son. Vive, lo que no son, es decir "relaciones directamente sociales de las personas en sus trabajos".

De ello resulta la forma bajo la cual Marx quiere ver la realidad: lo que no es, es también parte de la realidad que se ve y se vive. Entonces, la relación con la realidad puede ser solamente una relación real si muestra siempre de nuevo lo que no es.

Eso que no es, es lo ausente. Pero la ausencia que penetra lo que está presente y que parece ser lo real, es también una presencia, pero una presencia, que es ausencia presente. Hasta puede gritar, y el ser humano, que sufre esta ausencia puede acompañar este grito de la ausencia. Eso es el centro de lo que Marx reconoce como situación de clase: una clase dominante que niega esta ausencia y legitima de esta manera su lucha de clases desde arriba y una clase dominada y reprimida, que sufre esta lucha de clases y que entonces se levanta con una lucha de clases desde abajo en nombre de lo que no es, y por eso también, en nombre de lo que todavía no es.

Esta forma de argumentación aparece en Marx muchas veces. Así también, en los capítulos sobre la producción de la plusvalía:

El obrero no se limita a hacer cambiar de forma la materia que le brinda la naturaleza, sino que, al mismo tiempo, realiza en ella su fin, fin que él sabe que rige como una ley las modalidades de su actuación y al que tiene necesariamente que supeditar su voluntad. Y esta supeditación no constituye un acto aislado. Mientras permanezca trabajando, además de esforzar los órganos que trabajan, el obrero ha de aportar esa voluntad consciente del fin a que llamamos atención, atención que deberá ser tanto más reconcentrada cuanto menos atractivo sea el trabajo, por su carácter o por su ejecución, para quien lo realiza, es decir, cuanto menos disfrute de

142

Franz J. Hinkelammert

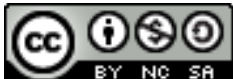

Revista Economía y Sociedad by Universidad Nacional is licensed under a CreativeCommons Reconocimiento-NoComercial- 
él el obrero como de un juego de sus fuerzas físicas y espirituales. (Marx, 1966, p. 131).

Ahora lo ausente es el "juego de sus fuerzas físicas y espirituales", que podría ser gozado, pero cuya ausencia se hace tanto más presente cuanto más el trabajo "rige como una ley las modalidades de su actuación y al que tiene necesariamente que supeditar su voluntad". Pero se trata nuevamente de aquello, en nombre de lo cual es exigido la presencia de aquello que está ausente.

Eso, lo que no es y cuya ausencia está presente, puede ser nombrado de manera muy diversa. En el capítulo sobre el fetichismo en el primer tomo de El capital Marx menciona como tal su modelo del Robinson social:

Finalmente, imaginémonos, para variar, una asociación de hombres libres que trabajen con medios colectivos de producción y que desplieguen sus numerosas fuerzas individuales de trabajo, con plena consciencia de lo que hacen, como una gran fuerza de trabajo social. En esta sociedad se repetirán todas las normas que presiden el trabajo de un Robinson, pero con carácter social y no individual.... Como se ve, aquí las relaciones sociales de los hombres con su trabajo y los productos de su trabajo son perfectamente claras y sencillas, tanto en lo tocante a la producción como en lo que se refiere a la distribución. (Marx, 1966, p. 43).

Por supuesto, Marx podría haber usador aquí cualquier otra de sus diversas expresiones para esta referencia al comunismo como lo ausente. Así, por ejemplo, su concepto del comunismo en los manuscritos filosóficos y económicos del año 1844, pero también su formulación de lo que es el socialismo, tal como lo presenta en el Manifiesto comunista, esto es como una "asociación, en la cual el libro desarrollo de cada uno es la condición del libre desarrollo de todos".

Al final del cuarto capítulo del primer tomo de El capital y, por tanto, inmediatamente antes de pasar a los capítulos sobre la plusvalía. Marx vuelve a resumir esta su concepción de la realidad:

La órbita de la circulación o del cambio de mercancías, dentro de cuyas fronteras se desarrolla la compra y la venta de la fuerza de trabajo, era, en realidad, el verdadero paraíso de los derechos del hombre. Dentro de estos linderos, solo reinan la libertad, la igualdad, la propiedad, y Bentham. La libertad, pues el comprador y el vendedor de una mercancía, v. gr. de la fuerza de trabajo, no obedecen a más ley que la de su libre voluntad. Contratan como hombres libres e iguales ante la ley. El contrato es el resultado final en que sus voluntades cobran una expresión jurídica común. La igualdad, pues compradores y vendedores solo contratan como poseedores de 
mercancías, cambiando equivalente por equivalente. La propiedad, pues cada cual dispone y solamente puede disponer de lo que es suyo. Y Bentham, pues a cuantos intervienen en estos actos solo los mueve su interés. La única fuerza que los une y los pone en relación es la fuerza de su egoísmo, de su provecho personal, de su interés privado. Precisamente por eso, porque cada cual cuida solamente de sí y ninguno vela por los demás, contribuyen todos ellos, gracias a una armonía preestablecida de las cosas o bajo los auspicios de una providencia omniastuta, a realizar la obra de su provecho mutuo, de su conveniencia colectiva, de su interés social. (Marx, 1966, pp. 128-129).

Hasta aquí Marx muestra la consecuencia ideológica de la reducción de la realidad social a la visión directa que uno recibe, si se interpreta exclusivamente desde la situación del propietario de las mercancías y, por tanto, asume exclusivamente el punto de vista de un observador.

Partiendo de eso, Marx hace ver cómo aparece una acción exclusivamente orientada a la lucha de clases desde arriba, que lleva a una situación en la cual lo ausente, que como ausencia está presente, se hace inmenso y penetra ahora esta realidad reducida:

Al abandonar esta orbita de la circulación simple o cambio de mercancías, adonde el librecambista vulgaris va a buscar las ideas, los conceptos y los criterios para enjuiciar la sociedad del capital y del trabajo asalariado, parece como si cambiase algo la fisonomía de los personajes de nuestro drama. El antiguo poseedor de dinero abre la marcha convertido en capitalista, y tras él viene el poseedor de la fuerza de trabajo, transformado en obrero suyo; aquel, pisando recio y sonriendo desdeñoso, todo ajetreado; este, tímido y receloso, de mala gana, como quien va a vender su propia pelleja y sabe la suerte que le aguarda: que se la curtan. (Marx, 1966, p.129).

Esta curtiduría es el lugar desde el cual lo ausente se hace mejor visible en su presencia o se puede hacer visible. Así se desemboca de nuevo en lo que según las palabras citadas de Marx del año 1859 es el comienzo del pensamiento marxiano, específico en el año 1844: que el ser humano es el "ser supremo para el ser humano" y que por tanto hay que echar por tierra todas las relaciones en las cuales el ser humano es "un ser humillado, sojuzgado, abandonado y despreciable".

Con eso Marx introduce la discusión sobre la plusvalía. Al final del análisis de la plusvalía relativa amplía este análisis con el resultado de que ahora la "curtiduría" abarca el mundo entero. Marx entonces dice:

En la agricultura, al igual que en la manufactura, la transformación capitalista del proceso de producción es a la vez el martirio del productor, en que el instrumento de trabajo se enfrenta con el obrero como instrumento de sojuzgamiento, de

144

Franz J. Hinkelammert

(c) (P) 8 (2)

Revista Economía y Sociedad by Universidad Nacional is licensed under a CreativeCommons Reconocimiento-NoComercial- 
explotación y de miseria, y la combinación social de los procesos de trabajo como la opresión organizada de su vitalidad, de su libertad y de su independencia indi. (Marx, 1966, p. 423).

Esto lleva a Marx a la perspectiva de un peligro de amenaza mundial, un juicio que hoy es compartido por la mayoría de la población mundial. Por tanto, la última frase del análisis de la plusvalía relativa resulta ser: "Por tanto, la producción capitalista sólo sabe desarrollar la técnica y la combinación del proceso social de producción socavando al mismo tiempo las dos fuentes originales de toda riqueza: la tierra y el trabajador" (Marx, 1966, p. 423). Según Marx esta es la tendencia forzosa del capitalismo salvaje, que solamente puede ser evitada en el grado en el cual este capitalismo es limitado, intervenido o abolido. De otra manera, la historia humana desemboca sencillamente en el suicidio colectivo de la humanidad.

\section{El asesinato del hermano como asesinato fundante}

El lado humanista de toda la argumentación vuelve a aparecer en Marx en un lugar muy destacado. Se trata del final de su edición del libro El capital, que se publicó por primera vez en 1867. Tiene en ese tiempo un solo tomo. Posteriormente, y después de la muerte de Marx, Friedrich Engels edita y publica dos tomos más a partir de manuscritos no publicados de Marx. Quiero presentar una cita, que se encuentra al final de toda su presentación de la crítica de la economía política en esa primera edición.

Esta edición tiene 25 capítulos, pero los capítulos 24 y 25 forman más bien un anexo referente a la historia del capitalismo, en especial a lo que Marx llama la acumulación originaria. Con el capítulo 23 termina su teoría de la crítica de la economía política. La cita que me interesa consiste de las últimas frases de este análisis, con las cuales termina el análisis principal en el capítulo 23. Como se ve, se trata de un lugar muy especial y simbólico. Es el final del análisis teórico de la más grande obra suya que Marx personalmente edita.

Escribe Marx: "Y frente a la vieja reina de los mares se alza, amenazadora y cada día más temible, la joven república gigantesca: "Acerba fata Romanos agunt, Scelusque fraternae necis," (Marx, $\underline{1966}$, p. 606$)^{4}$

Marx no traduce esta cita de Horacio del latín. Posteriormente, fue traducida, pero de una manera muy problemática y confusa. En la edición de El capital en español (edición Fondo de Cultura Económica) se traduce de la misma manera como en la alemana: "Un duro destino atormenta a los romanos y el crimen del fratricidio".

\footnotetext{
${ }^{4}$ Una traducción similar se encuentra en la edición de El capital de siglo XXI.
} 
Aparentemente aquí el "duro destino" no es producto directo del "fratricidio". Esta traducción es falsa. Tendría que decir: "Un duro destino atormenta a los romanos, el crimen del fratricidio"

Si citamos las siguientes dos líneas, que Marx no cita expresamente, este significado se hace más obvio todavía: "ut inmerentis fluxit in terram Remi sacer nepotibus crúor", esto es: "desde que corrió la sangre inocente de Remi a la tierra, [hay] una maldición para los descendientes". Donde en las primeras dos líneas hablaba Horacio de un "duro destino", ahora habla de una "maldición" para los descendientes.

Marx ahora denuncia este asesinato del hermano. Pero amplía el concepto del asesinato del hermano más allá del concepto que probablemente tiene en Horacio. Horacio se refiere a Rómulo y Remo. Con eso hace alusión a la guerra civil romana, que ocurre en el tiempo de la vida de Horacio. Horacio restringe el concepto de hermano a esta relación en el interior de un pueblo, que para él es el pueblo romano. Por tanto, matar a otro romano es asesinato del hermano, pero matar a un galo o un germano no lo es. Marx, sin duda, se refiere a un concepto de asesinato del hermano, en el cual todos los otros seres humanos son hermanos. En Marx es un concepto universal, que de hecho imputa a Horacio. Pensado el asesinato del hermano en nuestra tradición occidental, se refiere más bien al mito de Caín y Abel. Podemos concluir que Marx interpreta el texto de Horacio a la luz del mito de Caín y Abel, es decir, a la luz de un asesinato universal del hermano, cuyo mito corriente en nuestra tradición es el mito de Caín y Abel. Eso es el asesinato del hermano, como Marx lo concibe, pero refiriéndolo al texto de Horacio e interpretándolo a la luz del mito de Caín y Abel.

Lo interesante es que en la cita anterior Marx contrapone a la "vieja reina de los mares" (Roma en la antigüedad, Inglaterra en su tiempo, EE. UU. en nuestro tiempo) la "república gigantesca". Es la sociedad civil desde abajo, que constituye república y que no puede constituirse tal sin considerar el asesinato del hermano como asesinato fundante. Se trata de los movimientos de emancipación.

De esta manera resulta que para Marx la emancipación es sencillamente la otra cara de la superación del asesinato del hermano. Nuestro lenguaje en este campo, sin embargo, es sumamente limitado. No se trata solamente del asesinato del hermano en el sentido literal. Precisamente en el caso de la emancipación de las mujeres es necesario aclarar, que por lo menos en este caso el asesinato del hermano es un asesinato de la hermana. Frente a esta superación del asesinato del hermano (y de la hermana) aparece la negación de los mismos movimientos que muchas veces se hace en nombre de la condena del asesinato del padre. Cada movimiento de emancipación tiene que intervenir y cambiar el orden dominante, por eso es esta es negada y combatida en nombre del orden dominante. Pero el orden es defendido en nombre de esta autoridad dominante, que en última instancia es autoridad del padre, aunque solamente del padre de la patria. Por eso, no sorprende que, por ejemplo, Pinochet después del golpe militar en 146

Franz J. Hinkelammert

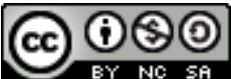

Revista Economía y Sociedad by Universidad Nacional is licensed under a CreativeCommons Reconocimiento-NoComercial- 
Chile sostuviera que todos los "subversivos" son asesinos del padre. Él se sentía el padre freudiano, que iba a ser asesinado.

Aquí se hace obvio el humanismo de Marx y además se muestra, que no se trata simplemente de un humanismo de nobles sentimientos, sino de un humanismo de la praxis. Aquí no suena solamente la novena sinfonía de Beethoven.

Esto me parece ser el núcleo de la dialéctica de Marx. Y me parece obvio también, que eso no es simplemente dialéctica hegeliana. La dialéctica hegeliana es una dialéctica del espíritu absoluto, que llega a ser saber absoluto. Aquí, en la dialéctica de Marx, el centro es la convivencia humana perfecta. Se trata de la imaginación de una convivencia humana perfecta, que es transformada en un objeto de la praxis humana, que la quiere realizar. Pero el orden establecido siempre es defendido en nombre de la autoridad vigente.

\section{El concepto de la praxis de Marx y su desarrollo como humanismo de la praxis hoy.}

Lo que Marx llama praxis es siempre vista en unión con el núcleo de la dialéctica de Marx. Creo que hay que seguir desarrollando esta dialéctica.

Esta dialéctica abre el espacio de diversas presentaciones de la praxis. Este espacio es enormemente amplio. Para ver eso, hay que tener presente las diferentes metas imaginables que Marx menciona como ausencias, cuya ausencia está presente. Por eso hay que mirarlas desde el punto de vista de la posibilidad de su realización práctica. En general, casi todas estas presentaciones, que Marx tiene presente, resultan imposibles en cuanto a su realización, o se han mostrado imposibles, cuando los países que se consideraban socialistas intentaron su realización.

Marx se atiene a una convicción que considera todos estos conceptos referidos simplemente como realizables o aproximadamente cerca de su realización. Marx lo dice muy claramente en el prólogo de 1859:

Por eso, la humanidad se propone siempre únicamente los objetivos que puede alcanzar, pues, bien miradas las cosas, vemos siempre que estos objetivos sólo brotan cuando ya se dan, o, por lo menos, se están gestando, las condiciones materiales para su realización”. (Marx, 1976a, p. 13).

Hoy no puede haber dudas, que metas como el comunismo, como Marx lo entiende, se encuentran fuera de nuestro espacio de posibilidades. Eso también vale para diversos elementos de este concepto. Si la realización de este comunismo implica la abolición de las relaciones mercantiles y del Estado, la imposibilidad de la realización del comunismo se extiende también, para estos elementos del concepto de este mismo comunismo. En la historia del socialismo se ha 
demostrado que tal abolición es imposible y que, por tanto, alternativas al capitalismo de hoy ya no deben ser pensadas en términos de la abolición de estos elementos. Además, de hecho, hoy en todas las versiones de la conceptualización del socialismo ya no se exige estas aboliciones.

Por esta razón, hoy la sociedad alternativa al capitalismo es una sociedad, que asegura una intervención sistemática del sistema de mercados, misma que tiene que ser realizada para que el capitalismo salvaje de hoy no pueda destruir nuestro mundo entero de la vida. Se trata de incrustar (Polanyi usa la palabra embedding) las relaciones mercantiles en las relaciones sociales de todos los seres humanos.

\section{¿Qué está ocurriendo con la conceptualización del comunismo de Marx y del marxismo que le sigue?}

El concepto del comunismo normalmente estuvo relacionado e incluso identificado con una meta de realización en relación a la sociedad humana en su conjunto. $Y$ el socialismo fue concebido como una sociedad que lleva a la realización definitiva del comunismo. La formulación más grandiosa de este concepto de comunismo la encontramos en los Manuscritos económicosfilosóficos de Marx del año 1844. Sin embargo, una definición clásica, que sea usada en todas partes, no la hay. Pero siempre se trata de alguna imaginación de una convivencia humana en gran medida perfecta, que incluye todas las dimensiones de la sociedad humana, sobre todo la dimensión económica. En el centro de esta imaginación siempre estaba la abolición definitiva de las relaciones mercantiles y del Estado en cuanto instrumento de dominación, y de la misma sociedad de clases. De eso se seguía, que también la propia religión desaparecería.

Eso es la imaginación -y hasta cierto grado, conceptualización- de un mundo perfecto, que precisamente en relación con nuestro mundo no puede ser una meta de realización. Se trata de un concepto de perfección de la convivencia humana, que muy bien se puede denominar con una expresión kantiana: se trata de un concepto transcendental. Se trata de una transcendentalidad en el interior de la inmanencia. Creer poder realizarlo, lleva en el lenguaje de Kant hacia "la ilusión transcendental", que puede tener consecuencias desastrosas. ${ }^{5}$ Sin embargo, la ilusión no es el propio concepto del comunismo. Este es simplemente el concepto de una convivencia humana perfecta, que en su forma de un concepto transcendental da un conocimiento efectivo: el conocimiento de lo que significa una convivencia humana en su perfección. En esta forma, desarrolla valores que están implicados en este concepto de una convivencia perfecta. Es perfectamente posible orientarse por estos valores, aunque el concepto perfecto apunte a algo imposible. Este concepto no puede ser una meta, pero sí puede exigir a todas las metas, que se orienten por estos valores de la convivencia en el grado que resulta posible.

${ }^{5}$ Es el problema de la crítica de la razón utópica. Cfr. Hinkelammert, 1984. 148

Franz J. Hinkelammert

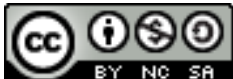

Revista Economía y Sociedad by Universidad Nacional is licensed under a CreativeCommons Reconocimiento-NoComercialCompartirlgual 4.0 Internacional License.

Creado a partir de la obra en http://www.revistas.una.ac.cr/index.php/economia 
El tránsito desde la imaginación del comunismo como meta hacia su imaginación como orientación por los valores, se hizo forzoso por la crisis y el colapso del socialismo soviético en 1989/1990. La incapacidad de ordenar el sistema de mercados ha sido una de las razones principales para este fracaso. Pero este causó daños extraordinarios. Y a pesar de eso, se sigue tratando hoy de una alternativa para el capitalismo actual autodestructivo, que se ha transformado en el proyecto de un suicidio colectivo de la humanidad y por eso, obliga a seguir buscando alternativas.

En última instancia, la convicción de la no factibilidad de las conceptualizaciones del comunismo obviamente ha debilitado todo el movimiento socialista. Se trata de un mito de imaginación de la factibilidad, que ha dominado toda la modernidad y la domina todavía en muchas partes. Esta forma de factibilidad absoluta hoy ya no es algo dominante en el pensamiento marxista y está superada en gran parte. De hecho, la dialéctica de Marx se transformó en una dialéctica transcendental. Pero en nuestra sociedad este tipo de mito de la factibilidad sigue muy presente, y lo es precisamente, en el neoliberalismo actual con su mito fundamental del automatismo del mercado y su autorregulación. Esa es una de las razones del gran peligro que presenta este neoliberalismo hoy. Aquí de nuevo se trata de aquello que Kant llamaba la "ilusión transcendental". En la tradición liberal y neoliberal esta ilusión transcendental está totalmente conectada con las imaginaciones del automatismo del mercado, de las fuerzas auto-reguladoras del mercado y de una providencia divina del mercado "omniastuta" (Marx), que se llama "mano invisible".

Esta conceptualización junto con su ilusión transcendental se puede reconocer fácilmente como el sueño de una sociedad perfecta. Pero la sociedad perfecta del neoliberalismo no es, como en el socialismo, la imaginación de una convivencia humana perfecta, sino la imaginación del tal llamado mercado perfecto con su competencia perfecta que todavía hoy casi todos los estudiantes de ciencias económicas tienen que estudiar en sus primeros años de estudios. El concepto transcendental de la competencia perfecta resulta entonces un medio para el lavado de cerebro de los futuros economistas, que por medio de este concepto transcendental son introducidos en la ilusión transcendental del mercado.

Se trata también de un concepto transcendental con su sueño de sociedad perfecta, pero se lo piensa desde una "competencia perfecta" y no desde una convivencia humana perfecta. Es la imaginación de una institución perfecta, es decir, de una ley perfecta. En este sentido se lo piensa desde la guerra, no desde la paz. Su correspondiente ilusión transcendental es el mercado total, como hoy es propagandizado por el neoliberalismo. ${ }^{6}$ Con eso se pasa de lo que Marx dijo: "El ser humano es el ser supremo para el ser humano" a lo que ahora pronuncia el neoliberalismo: el

${ }^{6}$ Cfr. Hinkelammert, Franz, $\underline{2018}$

Franz J. Hinkelammert

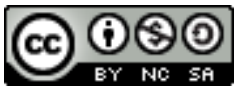

Revista Economía y Sociedad by Universidad Nacional is licensed under a CreativeCommons Reconocimiento-NoComercialCompartirlgual 4.0 Internacional License. Creado a partir de la obra en http://www.revistas.una.ac.cr/index.php/economia 
mercado es el ser supremo para el ser humano. Desde el comienzo de la estrategia de globalización en los años 80 aparece al lado de la competencia perfecta como concepto transcendental la nueva teoría de la firma, que es pensada como firma (empresa) perfecta y que a veces hasta sustituye el concepto de la competencia perfecta como concepto transcendental.

Estos conceptos transcendentales - sea del comunismo o de la competencia perfecta - de ninguna manera son utopías. Marx siempre insistió que su concepto del comunismo no es una utopía, aunque no se dio cuenta que se trata de un concepto transcendental. Siendo conceptos, estos conceptos transcendentales no son utopías, pero como conceptos son parte de las ciencias sociales y de su argumentación, y tienen que serlo. Sin embargo, las ciencias sociales dominantes apenas reflexionan sobre estos conceptos, aunque se los usa intensamente (como lo demuestra el uso del concepto de competencia perfecta). Pero casi no se los reflexiona. Max Weber inventa para ellos la palabra "tipo ideal", pero no logra hacer visible el problema. Se nota que nuestro concepto dominante de ciencias sociales es sumamente reducido.

\section{La nueva argumentación}

Quisiera mostrar ahora, cómo la superación de la ilusión transcendental en la interpretación del comunismo lleva a nuevos tipos de argumentación. Quisiera hacer ver eso primero con el ejemplo de Corbyn.

Jeremy Corbyn, el actual secretario general del partido laborista en Inglaterra ha presentado la meta de su ejercicio como secretario general de la siguiente manera: Nuestro trabajo es mostrar que la economía y nuestra sociedad pueden funcionar para todos. Eso significa garantizar que nos levantemos contra la injusticia donde sea que la encontremos y luchamos por un futuro más justo y más democrático que satisfaga las necesidades de todos (Corbyn, 2015 , p. 1) ${ }^{7}$

Es importante hacer ver, que ninguna de las conceptualizaciones que usa Corbyn aquí, pueden ser realizadas simplemente por el cumplimiento de alguna ley. No se trata de normas. Tampoco se trata de proposiciones de leyes o de la fundación de nuevas instituciones, sino que se trata de criterios de juicio para la acción política, cuya vigencia tiene que ser asegurada frente a todas las leyes e instituciones. En este sentido se trata de orientaciones éticas. A eso pertenece la consciencia de que la aplicación de tales criterios también se puede perder, sin que cambien leyes o instituciones en su existencia formal y sin que estas sean abolidas. Aquí el concepto de comunismo de nuevo puede encontrar lugar. Pero su interpretación tiene que ser otra. Por eso,

\footnotetext{
7 "Our job is to show that the economy and our society can be made to work for everyone. That means ensuring we stand up against injustice wherever we find it and we fight for a fairer and more democratic future that meets the needs of all." Recuperado de The Guardian online,13-9-2015.
}

150

Franz J. Hinkelammert

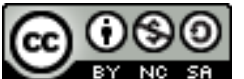

Revista Economía y Sociedad by Universidad Nacional is licensed under a CreativeCommons Reconocimiento-NoComercialCompartirlgual 4.0 Internacional License.

Creado a partir de la obra en http://www.revistas.una.ac.cr/index.php/economia 
conceptualizaciones como la del comunismo de Marx de 1844 vuelven a tener validez, pero ahora valen como orientaciones éticas, que expresan un sentido del desarrollo y lo exigen.

Lo que Corbyn desarrolla es la perspectiva que se refiere a todas las medidas que él quiere tomar. Hace ver lo que él entiende como el sentido de su acción. Es interesante ver que (conscientemente o no) se basa en dos fuentes. Cuando dice "que nos levantemos en contra de cualquier injusticia, donde la encontramos" de hecho nos recuerda a Marx y su imperativo categórico. Como vimos, Marx hace eso en su artículo "Crítica de la filosofía del derecho de Hegel - Introducción" del año 1844, que antes hemos citado. Allí dice que "el ser humano es el ser supremo para el ser humano" $y$, por consiguiente, presenta su "imperativo categórico de echar por tierra todas las relaciones en que el ser humano sea un ser humillado, sojuzgado, abandonado y despreciable". Marx, $\underline{1844}$, pp. 6-7.

La otra fuente se nota cuando Corbyn dice "luchamos por un futuro más justo y más democrático, que satisfaga las necesidades de todos." (Corbyn, 2015, p. 1). La fuente es lo que dicen los Zapatista en México, es decir, que se trata de un mundo en el cual todos tienen lugar, incluyendo la naturaleza entera. También alude a Gandhi. Lo que Corbyn expresa es una espiritualidad. A mi entender se trata de la espiritualidad, que hoy tiene que desarrollar cualquier posición de izquierda y que, por supuesto, es posible encontrar ya en muchos lugares, sobre todo hoy en América Latina.

\section{La recuperación de la emancipación humana}

Desde tiempo atrás aparece esta manera de ver un nuevo proyecto de una sociedad alternativa al capitalismo, especialmente en América Latina, que contesta directamente a la ilusión transcendental del mercado que el neoliberalismo formula e intenta imponer.

Hemos indicado, que el proyecto de Corbyn se inscribe en esta tradición, sea esta de Marx o de los actuales movimientos de izquierda en América Latina, aunque no la repite simplemente, sino que también la desarrolla. La base de este proyecto es lo que los Zapatistas en México han presentado como su perspectiva transformadora y que más tarde fue desarrollada en toda América Latina: una sociedad en la cual todos tienen lugar.

Esta es la visión alternativa en su forma objetiva. A la vez es elaborada en su forma subjetiva y aparece en diferentes formulaciones. Una es la que se elaboró en algunos países latinoamericanos a partir de una larga tradición indígena, como en Bolivia y Ecuador. En Bolivia se llama Suma Qamaña y en Ecuador Sumak Kawsay, lo que se puede traducir como buen vivir. No se trata del vivir bien aristotélico, que parte del individuo. Se trata más bien de una determinada convivencia, sin la cual no se puede vivir bien. Es algo que en África del Sur se llama: 
"yo soy, si tú eres", o "yo soy si vosotros sois", o variaciones similares. En África se llama el humanismo Ubuntu y tiene una larga tradición en muchas culturas africanas.

Las dos formulaciones coinciden. Una dice lo que esta sociedad, de la cual se trata, es cuando la miramos desde afuera. La otra dice, lo que son los sujetos de esta sociedad, que son su soporte. Se trata de una exigencia y referencia de orientación en cada momento y en cada lugar. Es la perspectiva del ser humano como ser viviente. Es lo que está implícito en el buen vivir boliviano. De hecho, es la respuesta al proyecto neoliberal de una sociedad sin derechos humanos que tiene solamente derechos del Mercado, es decir, derechos que se pueden deducir del derecho de propiedad privada. Es la perspectiva del ser humano como capital humano, en relación con la cual todos los que no sirven como capital humano o no quieren funcionar de esta manera, son considerados basura humana.

Al lado de estas alternativas posibles que se han abierto, surgió ya desde los años 60 del siglo pasado otra, que sigue teniendo gran importancia. Se trata de la teología cristiana de liberación. Empezó en América Latina, pero se extendió posteriormente, a muchos otros países en el mundo, como por ejemplo a Alemania y Suiza.

Hoy este proyecto de un mundo en el cual quepan todas las personas entra en muchas discusiones. Entra también en las discusiones sobre la descolonización de la propia cultura. Como proyección puede precisamente definir lo que está ausente y hace falta en toda relación del ser humano con su ser cultural, en todas sus relaciones con los otros. Es decir, de lo que se trata como orientación ética en el proceso de la descolonización de la propia cultura.

Se trata hoy, frente al neoliberalismo, de no seguir basando el cuestionado "desarrollo" en la ilusión transcendental de la privatización de todo lo que se puede de algún modo privatizar, sino en la ampliación del desarrollo social y ecológico y en el desarrollo de las correspondientes intervenciones en el mercado, que tienen que desarrollar tanto el Estado social como también el Estado ecológico.

Se trata de la espiritualidad del humanismo de la praxis, como fue presentado por Marx y que hoy tiene que dar la respuesta a la reducción de toda espiritualidad a la espiritualidad del dinero, como está ocurriendo en nuestra actual religión neoliberal del mercado.

\section{La dialéctica de Marx}

He intentado hacer ver una dialéctica propia de Marx, misma que hoy necesitamos para movilizar las fuerzas democráticas de los movimientos populares de izquierda y contestar a la lucha de clases desde arriba, que es impuesta de nuevo con fuerza inaudita, con una democracia desde abajo, una democracia de la "gran república gigantesca".

152

Franz J. Hinkelammert

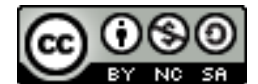

Revista Economía y Sociedad by Universidad Nacional is licensed under a CreativeCommons Reconocimiento-NoComercial- 


\section{Referencias}

Corbyn, J. (September 13, 2015). Britain can't cut its way to prosperity. We have to build it. The Guardian. Recuperado https://www.theguardian.com/commentisfree/2015/sep/13/jeremy-corbyn-labourleadership-victory-vision

Feuerbach, L. (1956). Gesammelte Werke, Band 5 Das Wesen des Christentums. Berlin. Achunfzwangzigstes Kapitel, S. 508.

Harnecker, M. (1969). Los Conceptos elementales del materialismo histórico (primera edición). Siglo veintiuno editores: México.

Harnecker, M. (17 de marzo de 2016). El legado de Louis Althusser al marxismo. Rebelión. Recuperado de https://www.rebelion.org/noticia.php?id=210007.

Hinkelammert, F. (1984). La crítica de la razón utópica. Recuperado de http://www.pensamientocritico.info/index.php/libros/libros-de-franzhinkelammert/espanol

Hinkelammert, F. (2018). Totalitarismo del mercado. El mercado capitalista como ser supremo. Recuperado de http://www.pensamientocritico.info/index.php/libros/libros-de-franzhinkelammert/espanol?start=20

Marx, K. (1844). Crítica de la filosofía del derecho de Hegel. Recuperado de http://archivo.juventudes.org/textos/Karl\%20Marx/Critica\%20de\%20la\%20Filosofia\%20 del\%20Derecho\%20de\%20Hegel.pdf

Marx, C. (1976a). Contribución a la crítica de la economía política. Ediciones de Cultura Popular: México.

Marx, C. (1976b). Tesis sobre Feuerbach. En C. Marx y F. Engels, Obras Escogidas, (7-11). Editorial Progreso: Moscú.

Marx, K. (1964). La introducción a la crítica de la filosofía del derecho de Hegel. Crítica de la religión. En Erich Fromm (comp), Marx y su concepto del hombre, (230). Fondo de Cultura Económica: México.

Marx, K. (1966). El capital (tomo I). México: Fondo de Cultura Económica. 